\title{
Proposal Strategy and Policy on Nuclear Safety for No-More Severe Accidents
}

\author{
-Proposal for Countermeasures to Prevent Severe Accidents \\ at Nuclear Power Plants-
}

\section{Committee on Prevention of Severe Accidents at Nuclear Power Plants}

The 2011 off the Pacific Coast of Tohoku Earthquake, which had a magnitude of 9.0, and the catastrophic tsunami that followed on March 11, 2011, struck five nuclear power stations located on the Pacific coast, thereby triggering a severe accident involving an extensive release of radioactive materials at the Fukushima Daiichi Nuclear Power Plant (NPP) operated by the Tokyo Electric Power Company (TEPCO). It was Professor Hiroyuki Abe, the former president of Tohoku University, who proposed the establishment of the Committee on Prevention of Severe Accidents at Nuclear Power Plants with the following statement: "How could the severe accident that occurred at TEPCO's Fukushima Daiichi NPP have been prevented? We must lose no time in determining the necessary measures that should have been in place to prevent this accident. Given that a nuclear power plant is primarily a product of technological development, it is the mission of the scientists and engineers engaged in promoting nuclear technology and nuclear safety to address and clarify the measures necessary to prevent a severe accident." The committee was established according to his proposal.

Although the Fukushima Accident was caused by an immense tsunami that was triggered by a massive earthquake, scientists and engineers who have dedicated themselves to research and development in the nuclear technology field for so many years are overwhelmed with sorrow and regret for the broad and severe devastation suffered by local residents and the rest of the nation.

Vowing that such a severe accident will never happen again, nuclear scientists and engineers have gathered to address fundamental issues concerning the re-establishment of preventive measures based on scientific and technological grounds.

\section{Introduction}

Over 40 years have passed since light-water reactors (LWRs) were first introduced for commercial nuclear power generation in Japan. The experience that Japan has accumulated in relation to research results and technological developments aimed at resolving numerous past

DOI : 10.15669/fukushimainsights.Vol.2.150

(c) 2021 Atomic Energy Society of Japan. All rights reserved.

Originally published in Journal of the Atomic Energy Society of Japan (ISSN 1882-2606), Vol. 55, No. 5, p. $292-297$ (2013)

in Japanese. (Japanese version accepted: March 14, 2013) 
failures and accidents has helped fortify and enhance the technological basis of LWRs. Currently, Japan is leading the way in LWR technology globally in terms of reliability and safety.

During the 2011 off the Pacific Coast of Tohoku Earthquake that occurred on March 11, the Fukushima Daiichi Nuclear Power Plant (Tokyo Electric Power Company) and the Onagawa Nuclear Power Plant (Tohoku Electric Power Company) registered responses that exceeded their design basis with respect to some aspects of seismic motion. However, when the earthquake hit, the reactors were immediately scrammed to perform a normal shutdown, and all of the key safety components, structures and systems related to the cooling and isolation of radioactive materials were functional and judged to have not been directly affected by the earthquake ${ }^{1)}$.

So, what caused this severe accident ${ }^{\mathrm{a}}$ at Fukushima Daiichi NPP?

The direct cause of the accident was that multiple overlapping tsunami waves that had been generated by multiple seismic fault movements along the ocean trench off the coast of the Fukushima Daiichi NPP struck the plant with a wave height exceeding $15 \mathrm{~m}$, a magnitude that far exceeded the design basis. This was considered an unprecedented event that no one had anticipated.

Japan's trust in nuclear technology—including its systems and components-is founded on the high quality of its design and manufacturing within the spectrum of a defense-in-depth of up to Level 3 under the International Atomic Energy Agency (IAEA) standards indicated in Table 1. The design and manufacturing standards established in Japan produced systems and equipment with very high reliability within the scope of design. However, because sufficient consideration had not been given to design requirements in relation to severe accidents caused by extreme natural phenomena that exceed the design basis or the establishment of countermeasures for such events, the designed safety facilities failed to function during the Fukushima Daiichi Accident.

Consequently, the major issue to be addressed is the establishment of a systematic approach to preparing for and responding to severe accidents that exceed the design basis.

In a safety assessment for the restarting of an existing plant in operation, it is necessary to evaluate its adequacy in relation to design criteria up to Level 3 (based on accumulated

Table 1 Defense-in-depth levels of IAEA

\begin{tabular}{|c|l|l|l|}
\cline { 2 - 4 } \multicolumn{1}{c|}{} & $\begin{array}{c}\text { Levels of } \\
\text { protection }\end{array}$ & \multicolumn{1}{|c|}{ Objective } & Corresponding plant condition \\
\hline \multirow{2}{*}{$\begin{array}{c}\text { Design } \\
\text { basis }\end{array}$} & Level 1 & $\begin{array}{l}\text { Prevention of abnormal } \\
\text { operations and failures }\end{array}$ & Normal operation \\
\cline { 2 - 4 } & Level 2 & $\begin{array}{l}\text { Control of abnormal operations } \\
\text { and detection of failures }\end{array}$ & $\begin{array}{l}\text { Anticipated operational } \\
\text { occurrences (AOO) }\end{array}$ \\
\cline { 2 - 5 } $\begin{array}{c}\text { Beyond } \\
\text { design } \\
\text { basis }\end{array}$ & $\begin{array}{l}\text { Control of accidents within the } \\
\text { design basis }\end{array}$ & $\begin{array}{l}\text { Accidents within the design basis } \\
\text { (A single, anticipated initiating } \\
\text { event) }\end{array}$ \\
\hline $\begin{array}{c}\text { Emergency } \\
\text { response }\end{array}$ & Level 5 & $\begin{array}{l}\text { Control of severe plant conditions, } \\
\text { including prevention of accident } \\
\text { progression and mitigation of the } \\
\text { consequences of severe accidents }\end{array}$ & $\begin{array}{l}\text { Multiple failures } \\
\text { Severe accidents }\end{array}$ \\
\hline
\end{tabular}

\footnotetext{
"Severe accident: The term "severe accident" is conventionally used by regulatory bodies, but the term "major accident" is used in the Act for Establishment of the Nuclear Regulation Authority. This commentary adopts the commonly used term "severe accident" to convey the meaning of an event that far exceeds the design basis event, prevents proper core cooling or reactivity control by the means anticipated in the assessment of safety design, and leads to serious core damage.
} 
reliability of the design and manufacturing processes). Furthermore, it is also necessary to extend severe accident management to within the spectrum of defense-in-depth Level 4 and implement a mechanism for ensuring continuous improvements in view of the devastating impact of the Fukushima Daiichi Accident. For this purpose, preparedness and response measures against large-scale earthquakes and tsunamis must be fully ensured and a prompt process for establishing appropriate measures against Level 4 incidents caused by factors other than earthquakes and tsunamis must be implemented by taking into account the specific design and siting conditions of each plant.

\section{Analysis}

\section{Approach to Defense in Depth}

Until now, ensuring the safety of nuclear reactor facilities in Japan has been focused on the management of design basis accidents ${ }^{2,3}$. This approach was based on three principles: the three levels of defense-in-depth (prevention of abnormal operations and failures, control of abnormal operations, and control and mitigation of accidents within the design basis); the configuration of important systems based on single-failure criterion; and correspondence for assumed external events such as earthquakes and tsumanis, etc. within design basis.

However, after the Three Mile Island Accident in the United States and the Chernobyl Accident in the former Soviet Union, the global community became more keenly aware of the significance of the extended consideration of beyond design basis events, or severe accidents, and the enhancement of protection measures against such events. In Japan, this issue was discussed and examined by the now defunct Nuclear Safety Commission (NSC). In May 2002, the NSC made strong recommendations on beyond design basis events within the spectrum of defense-in-depth Level 4, encouraging utilities to independently establish accident management measures (AM; the prevention of severe accidents and mitigation of any consequences that may occur) and take the provisions necessary to accurately implement such measures in the event of an accident. The recommended accident management measures for preventing an incident escalating into a severe accident and mitigating any consequences that may occur included taking advantage of the capacity margin of existing safety systems, using the functions of existing systems for purposes beyond their design intention, and using systems newly installed for AM purposes. The NSC requested the utilities and the former Ministry of International Trade and Industry (MITI; later this authorization was transferred to the Nuclear Industrial and Safety Agency) to manage and report on accident management measures.

In accordance with this policy, MITI promoted measures against severe accidents through administrative guidance and asked utilities to report on the measures that they put in place. The safety measures carried out by utilities remained voluntary. Accidents that may escalate into severe accidents beyond the magnitude of the design basis accident were not explicitly regulated as events within the scope of Level 4 defense in depth. Practices in Japan, including the policy of addressing severe accidents in the design of a new plant, were not necessarily lagging behind global trends, but Japan failed to establish regulatory requirements that kept pace with other countries.

In June 2012, the Act for Establishment of the Nuclear Regulation Authority was enacted in response to the accident that occurred at the Fukushima Daiichi Nuclear Power Plant. This act marked a transition to the adoption of safety regulations that also postulate major natural disasters and terrorism. In other words, the prevention and mitigation of events that may lead 
to severe accidents with a magnitude beyond that of the design basis are classified as Level 4 defense in depth.

The necessary equipment, apparatus, and other items must be installed with sufficient consideration given to factors such as redundancy, diversity, independence, reliability, and importance classification.

\section{Analysis of TEPCO's Fukushima Daiichi NPP Accident}

When the earthquake hit the Fukushima Daiichi NPP on March 11, all of the operating plants scrammed automatically into a cold shutdown. However, the impact of the tsunami that followed far exceeded the design assumptions, so this outcome had not been given due consideration in the safety measures. The tsunami event triggered a common-cause failure of extensive systems, including the loss of redundant or diverse systems, thereby inducing station blackouts and a subsequent loss of core cooling, a loss of ultimate heat sink, and eventually core damage (core melt). This caused a hydrogen explosion and a failure to contain radioactive materials, which led to a significant release of radioactive substances into the environment. This catastrophe was initiated by an external event. This gives an overview of TEPCO's Fukushima Daiichi Accident ${ }^{4}$.

The key issues to be addressed are vulnerabilities in terms of the following: assumptions concerning the functional failure of multiple units; assumptions concerning common-cause failures and accidents; and measures for dealing with these conditions. Specifically, the simultaneous failures and functional loss of safety components installed in multiple units at a site, or the overlapping of multiple failures or accidents, were not taken into account in previous assumptions. The tsunami that struck the Fukushima Daiichi NPP induced multiple simultaneous component failures, including the loss of redundant components in multiple units all at once. The essential events that led to such a severe accident were 1) a station blackout; 2) a loss of cooling systems; and 3) a loss of ultimate heat sink.

On the other hand, inadequacies in terms of accident management include a failure to address the following: 1) deficiencies in or shortages of alternate power sources; 2) deficiencies in the alternate pump capabilities (e.g., fire engines); and 3) unanticipated events (station blackout, hydrogen explosion, containment vessel damage, etc.).

These inadequacies and deficiencies were the outcome of our own limited assumptions concerning accident scenarios, with no consideration whatsoever given to accidents like the unanticipated aspects of the Fukushima Daiichi Accident. Until then, accident scenarios had been based on assumptions concerning internal events initiated by a single failure of the constituting components. This approach was based on the assumption that, if a one-by-one analysis of such scenarios was performed thoroughly and systematically, it could serve as a replacement for a quantitative (objective) assessment to ensure plant safety. Damage to multiple units due to the simultaneous failure of components with the same functions and common-cause failures were considered extremely low probability events in past assessments. The postulation and consideration of worst-case scenarios are critically important. An inadequate understanding of the accident sequences-including when fuel damage begins, how a containment vessel is damaged, and what happens after a vessel is damaged - and a lack of measures to address them led to us only reacting to events and falling behind during the disaster at the Fukushima Daiichi NPP ${ }^{5)}$. 


\section{Assessments}

\section{Measures for Unanticipated Events}

- In nuclear safety, the fact that something was not anticipated is not an acceptable excuse. The regulatory body and utilities should establish a framework that facilitates emergency preparedness and responses for all credible natural disasters, human-induced and internal events, and other such eventualities by thoroughly examining and identifying them.

The magnitude of the 2011 off the Pacific coast of Tohoku earthquake and the subsequent catastrophic tsunami was far beyond the design assumptions. In view of the potential risk associated with the large amount of radioactive materials contained in the reactor core, it is not acceptable to disregard natural disasters or external human-induced events as something unanticipated in crisis management. Full consideration must be given to preventing any adverse consequences for members of the public in the vicinity and the environment that may arise due to a significant release of radioactive materials. This should be engraved in the minds of all those engaged in the design, construction and operation of nuclear plants and related facilities. A constant process of applying new technologies, expertise, and the results of $\mathrm{R} \& \mathrm{D}$ in the design, operation and regulatory requirements for nuclear plants is necessary.

Responsibility for the surveillance and monitoring of emergency preparedness and accident prevention measures rests with the government and the regulatory body under the nuclear safety regulatory framework. It is necessary to establish regulatory requirements for the biannual submission by the utilities of "Severe Accident Prevention Plans," which contain reports on credible accident scenarios for natural disasters, human events and internal events; response management plans; the implementation status of emergency response training; and other such information for each plant. The regulatory bodies must take responsibility for establishing a system for reviewing and approving the planned countermeasures. Going beyond the regulatory framework, utilities must constantly look out for any events that may lead to severe accidents and try to develop countermeasures.

\section{Development of Performance-Requirement-Based Standards}

- All of the safety review guidelines and standards should be reviewed and modified as necessary without any preconceptions for the establishment of a systematic, performance-requirement-based ${ }^{\mathrm{b}}$ regulatory framework.

A "Fundamental Concept on Nuclear Safety" should be established to ensure the safety of nuclear power plants in Japan by referring to the IAEA Safety Standards and tailoring them to the prevailing circumstances here. Based on this "Fundamental Concept of Nuclear Safety," a framework for safety objectives, performance objectives, and fundamental policies on safety regulations should be developed at an early stage.

In addition, for example, "Guideline 27: Design Considerations against Loss of Power" of the Safety Design Guidelines ("Regulatory Guide for Reviewing Safety Design of Light Water Nuclear Power Reactor Facilities") of the NSC stipulates that "a nuclear power plant shall be so designed to ensure safe shutdown and adequate cooling thereafter in case of a shortterm station blackout (SBO)." However, the commentary for Guideline 27 states the following:

\footnotetext{
${ }^{\mathrm{b}}$ Establishment of performance-requirement-based technical standards by the regulatory body: The regulatory body should establish technical standards (codes and regulations) that are focused on performance requirements but provide flexibility in the selection of specifications for achieving the required performance.
} 
"the occurrence of a long-term SBO need not to be considered since recovery of a power transmission line or emergency diesel generator (EDG) should be expected." This will also be a factor behind the total lack of measures against power loss in the event of an SBO incident. All key safety components and equipment should be instrumented so that the probability of a common-cause failure is kept as low as possible and to ensure redundancy. If this is not feasible, diversity in terms of a combination of different functions and a distributed arrangement should be considered. It is also necessary to clarify the requirements for seismic resistance and radiation resistance in "Guideline 44: Emergency Station in Nuclear Power Plant" and whether an isolated reactor cooling function should be included with respect to "Guideline 42: Reactor Shutdown Function from Outside of Control Room." Together with the revision of the Seismic Design Guidelines ("Regulatory Guide for Reviewing Seismic Design of Nuclear Power Reactor Facilities"), an independent set of guidelines on associated events, particularly tsunami events, should be established. Similarly, the Review Guide for Safety Evaluations should establish a safety assessment method for severe accidents within the domain of defense-in-depth Level 4.

As such, in parallel with a systematic reorganization of laws, governmental and ministerial ordinances, and technical standards, the government should entrust professional societies in the civilian sector with establishing codes and specifications (for the actual implementation of regulatory standards) to ensure the prompt application of the results of state-of-the-art technologies and promote a performance-requirement-based regulatory structure. A systematic, performance-requirement-based nuclear safety framework should be established as quickly as possible.

\section{Enhancement of Management Measures and Human Resource Development}

- Substantial management measures related to nuclear safety should be implemented and the quality of personnel directly involved in operations should be improved.

The quality of the onsite emergency staff who managed the accident undoubtedly influenced recovery operations at the Fukushima Daiichi NPP. Although the onsite staff had regular training, the fundamental concept of nuclear safety-i.e., the basis for the training and safety measures-did not anticipate a severe accident of this scale. Naturally, the operators cannot be blamed for any failure of their part in responding to this unanticipated emergency. At the same time, a more appropriate response could perhaps have been taken if the operators had acquired a basic understanding of nuclear power generation and nuclear reactions.

The sequence of events that lead to a severe accident will never progress along the lines of a scenario. Given this, it is necessary to stipulate the regulated assignment of accident management specialists with the following attributes to each nuclear power site, or preferably each plant: a thorough understanding of nuclear power generation systems and the ability to make accurate judgments concerning event sequences in order to provide the necessary directions to onsite staff. The accident management specialist should possess professional expertise and competence in accident management and be able to advise the site director on matters such as the installment of necessary facilities and the allocation of the staff required for the implementation of accident management. In an emergency, the accident management specialist will support the site director in deliberations, decision-making, and the authorization of accident management operations. The regulatory surveillance and monitoring officer assigned to each site should be a technical expert with the same qualifications as the accident management specialist and be responsible for ensuring safety by liaising with the utilities.

A "Severe Accident Management Procedure Manual" should be developed for each power 
plant, with each item having been confirmed on site (they should not be confirmed only through deskwork), and then submitted to the regulatory body and shared with the surveillance officer. Together with the "Severe Accident Prevention Plans," this manual should be reviewed and revised on a biannual basis, for example. Because of the expected complexity of the manual's content, the document should preferably be digitalized and made available to the operating staff and workers so that they can implement the measures promptly.

The education and training of plant and site directors, managers, duty supervisors, duty staff, and other personnel should be provided frequently and on a regular basis so that response actions can be taken promptly under any circumstances, day or night, and under extreme weather conditions. It is essential that management measures related to nuclear safety be implemented and enhanced and the quality of personnel be improved by both the utilities and the regulatory body. At the same time, the regulatory body, utilities and manufacturers should coordinate joint regular meetings for information sharing and open sessions or observe plant construction work and commissioning by other utilities for the overall enhancement of the nuclear power industry. Furthermore, it is preferable that academic societies comprised of experts in the nuclear field provide appropriate advice as necessary.

\section{Continuous Efforts to Reduce Risks and Share Information with the Public}

- The government and utilities are responsible for the continuing process of building consensus and gaining public confidence concerning the benefits and risks of nuclear power generation. Scientists and experts in the nuclear technology field must also establish and maintain dialogue with the public on the benefits of nuclear power generation, which does not necessarily guarantee absolute safety so it should be balanced against the risks.

When communicating with the public in the past, the utilities (and related parties involved in nuclear technology) have emphasized the absolute safety, or the safety myth, of nuclear power plants. Some point out that this may be one of the factors to have hampered the appropriate establishment of severe accident management.

Dedicated and continued efforts in fostering an attitude that prioritizes nuclear safety are essential. Such efforts are required of the utilities and regulatory body as well as scientists and engineers in the field.

A continuing process of verifying and validating nuclear safety should be established by incorporating new scientific and technological findings in related fields, including natural disasters and human events, as well as the operating experiences of facilities and the results of safety research. To ensure the process of verifying and validating nuclear safety, it is necessary to enhance transparency in the examination and application of new findings as well as communication with the public regarding the status and issues.

The significance of the risks involved was recognized by some nuclear technology experts and part of the nuclear industry community. Research had been conducted into severe accidents and design studies for new LWRs equipped with severe accident countermeasures. Unfortunately, however, the overall awareness and understanding that a portion of the community had of the risks involved were not utilized in the severe accident management of existing NPPs. As scientists, researchers, and engineers, we must reflect deeply on our failure to raise awareness of these risks among utilities, regulatory bodies, and the public as well as the lack of adequate explanations of the necessary measures. At the very least, we need to admit that our efforts to do so were not sufficiently proactive.

Professional societies should and must establish dialogue with the public to formulate a 
shared recognition of risk.

The following are some points that should be noted in relation to establishing dialogue with the public.

\section{(1) Benefits and risks}

There is no absolute safety associated with any particular kind of system (railways, aircraft, cars, etc.). The benefits generated by the use of nuclear power, like those of other types of systems, will inevitably involve physical, mental, or financial risks.

\section{(2) Issues concerning minimizing risk (safety goals) ${ }^{6}$}

Nuclear power generation offers various advantages over other energy sources. However, it involves the generation of radioactive nuclides (or fission products) that arise from the enormous amount of energy released by the reaction within the atomic nuclei, as uranium or plutonium. The reactor needs to be cooled continuously after a shutdown because of the decay heat generated by the fission products, and the radioactive nuclides must be contained to prevent their release into the environment. In the Fukushima Daiichi NPP Accident, safety functions related to cooling and containment failed, thereby subjecting the local and national public to devastating damage and losses. Accident risks must be minimized to the extent possible, but how much risk can be accepted as safe?

"How safe is safe enough" has been part of the international agenda, so many countries have adopted safety goals presented as probabilistic figures and are using them to effectively complement deterministic rules. In Japan, the former Nuclear Safety Commission (NSC) proposed its "Safety Goals (draft)" after examining this issue. In their proposal, the safety goals were given the role of specifying the extent to which safety regulations by the government will be imposed on utilities' management of risks associated with low probability events. The proposal quantitatively clarified the required levels of risks associated with the use of nuclear energy that need to be regulated. It was the intention of the NSC that this clear definition should enhance the transparency, predictability, rationality, and consistency of the regulatory activities. It was also expected that safety goals expressed in terms of the risk to the public would enable the government and the public to exchange views effectively and efficiently on various regulatory activities, including the development of guidelines and standards. The proposed goals were presented on three levels: qualitative goals, quantitative goals, and performance goals. The qualitative goals (i.e., the top level goals) require that the likelihood of any adverse health consequences to the public arising from the release of radiation or radioactive materials due to the use of nuclear energy should not significantly increase health risks to the public to a level above that expected from everyday life.

Quantitative goals present specific numerical values that are embodied in qualitative goals. For example, the mean value of an acute fatality risk due to radiation exposure resulting from a nuclear facility accident in relation to members of the public in the vicinity of the site boundary of the nuclear installation shall not exceed the probability of approximately $1 \times 10^{-6}$ per year, and the mean value of the fatality risk due to cancer caused by radiation exposure resulting from a nuclear facility accident in relation to members of the public residing in the area but at some distance from the facility should not exceed the probability of approximately $1 \times 10^{-6}$ per year. The people that these goals apply to are limited to residents living in the vicinity of the site boundary of the nuclear installation, and the risk of radiation exposure is $1 / 50$ of the annual fatality rate for car accidents. The performance goals use parameters describing the characteristics of the facilities to express rough indicators that allow conformity with the safety goals to be easily verified. The given figures are the core damage frequency $(\mathrm{CDF})$ of $10^{-4}$ /reactor year and the containment failure frequency (CFF) of 
$10^{-5}$ /reactor year (representing the facility performance in relation to the integrity of the reactor core and containment function) in accident scenarios including internal and external initiating events (except for malicious or deliberate human events). However, these figures are not to be applied as fixed values. The requirement is as follows: "In all activities involving a nuclear installation, including its design, construction and operation, reasonably feasible risk reduction measures must be planned and implemented to ensure that the radiation risk to the public does not exceed 1 millionth annually and that, if necessary measures are planned and implemented on the basis of the proposed requirements described above, then it would not mean that the safety goal is not fulfilled even if the result of a risk assessment exceeds the value of 1 millionth." (Refer to "Interim Report on the Investigation and Review of Safety Goals," Special Committee on Safety Goals, Nuclear Safety Commission, December 2003.)

In view of TEPCO's Fukushima Daiichi NPP Accident, the method used in the selection of the above figures and indices should perhaps be modified. However, establishing dialogue with the public is extremely important in building consensus concerning the level of risk that is acceptable and can be agreed on by the people. The results of an examination incorporated into the draft Safety Goals would be useful as the basis for such dialogue.

\section{(3) Providing sufficient information}

A prerequisite for the effective use of safety goals and performance goals is for the results of a probabilistic risk assessment (PRA) to be explained together with the limitations and uncertainties associated with the assessment. For example, in NSC's draft "Safety Goals," both internal and external events need to be considered as initiating events. Unfortunately, a PRA ${ }^{\mathrm{c}}$ for external events such as earthquakes and tsunamis had not been conducted at TEPCO's Fukushima Daiichi NPP. This failure revealed that comparisons between assessment results and safety goals are meaningless unless risks are assessed by taking into account a wide range of events. Going forward, the risks involved should be explained to the public by clarifying the scope of the assessment, the policy for assessing any risk factors beyond this scope, and how any remaining risks are taken into account. If it is difficult to determine whether a safety goal has been satisfied due to a high degree of uncertainty concerning the assessment method, it is important to explain how much of a reasonably feasible effort is being made. We need to understand that discussions on the acceptance of the risks involved cannot take place otherwise. The efforts involved in providing the details and grounds for a risk assessment are closely tied to the activities conducted to gain the understanding of the public on the meaning and importance of various specific safety measures taken by the regulatory body and utilities. For this reason, these activities should be carried out in parallel.

\section{Recommendations}

Based on the above discussions, our committee recommends the following principles.

\section{Recommendation 1:}

In nuclear safety, the fact that something (any natural hazard, human error, etc.) was not anticipated is not an acceptable excuse. Efforts for eliminating unanticipated events are crucially important.

Recommendation 2:

A framework for ensuring nuclear safety should be established, whereby, safety review

\footnotetext{
" PRA/PSA: The terms "probabilistic risk assessment" (PRA) and "probabilistic safety assessment" (PSA) are synonyms for
} methods used to evaluate nuclear safety. 
guidelines and standards on safety should be reevaluated without being subject to preconceptions for developing a globally respected framework of nuclear safety.

Recommendation 3:

All related parties in the nuclear community should recognize responsibilities commensurate with assigned roles and establish the overriding priority in ensuring safety. The regulatory body, in particular, must determine fundamental principles for the prevention, and mitigation, of the consequences of severe accidents (defense-in-depth Level 4) by hearing the opinions of a broad spectrum of experts. The utilities should determine severe accident measures and effectively implement them with a sense of vigilance.

Recommendation 4:

The government and the utilities should independently or jointly-together with scientists and experts in the nuclear technology field through professional societies-establish risk communication with the public concerning nuclear power generation as well as promote activities aimed at establishing public consensus on the benefits and risks of nuclear power generation.

The following recommended specific measures are intended to support the above recommendations.

\section{Recommendation 5:}

The regulatory body should regulate plans and inspections on severe accident prevention and mitigation measures within the domain of defense-in-depth Level 4 that are proposed and prepared by the utilities. In the examination of such measures, all internal events (including human error events, etc.), natural phenomena and human-induced events associated with severe accidents should be included. By liaising with experts and utilities, the regulatory body should construct effective measures (accident management) by conducting deliberations on the combination of a broad spectrum of response strategies, including the use of a variety of components and equipment, for preventing severe accidents and mitigating the consequences if one occurs.

Recommendation 6:

Reliability of safety functions corresponding to the domain of defense-in-depth Level 4 should be ensured through elimination of common-cause failures, by ensuring independent effectiveness through distributed arrangement and diversification of safety functions.

Recommendation 7:

Specific measures for accident management should be flexible as to address unanticipated conditions which may not be dealt with by permanent facilities. Thus, transportable and mobile facilities (fixed on vehicles) and redundant connections should be provided for flexibly coping with all circumstances.

\section{Recommendation 8:}

Utilities should assign onsite accident management specialist(s) with a thorough understanding of nuclear power generation systems, having the competence to accurately understand or recognize situations likely to occur in a nuclear reactor under accident conditions and the ability to make appropriate judgments in providing necessary directions to onsite staff. Recommendation 9:

Utilities should prepare an accident management procedure manual in which each item must be confirmed on site on the basis that education, training, drills and exercises under all credible conditions should be fully provided to the staff.

Recommendation 10:

The regulatory body should conduct inspections and surveillance on accident management 
without omission. Utilities and the regulatory body should independently, or in cooperation, carry out reassessments for the continued enhancement of accident management.

\section{Conclusions}

Our committee hopes that this commentary will provide scientists, engineers, and other persons involved in the nuclear sector with input materials for discussions on preventing the recurrence of a severe accident. We also hope that it will help the general public to consider the risk-benefit trade-off involved in nuclear power generation.

This committee has been established as part of the activities of Japan Association of Technology Executives under the auspices of Watanabe Memorial Foundation for the Advancement of New Technology. We would like to express our deep gratitude to Mr. Hiroto Ishida for supporting our committee, Mr. Kazuki Okimura and Mr. Shizuo Hoshiba for their operational support, and all other parties who contributed to our technical discussions. We would also like to take this opportunity to thank Mr. Shojiro Matsuura, president of the Japan Nuclear Safety Institute, for sharing his views on our activities from a wide range of perspectives.

Lastly, the co-authors of this commentary are listed below.

Co-authors: Shinzo Saito (Committee Chair, Radiation Application Development Association), Kenichiro Sugiyama (Hokkaido University), Yutaka Nakahara (Mitsubishi Research Institute), Hideki Nariai (University of Tsukuba), Keiji Miyazaki (Osaka University), Hiroshi Miyano (Hosei University), Ken Muramatsu (Tokyo City University), and Masaaki Matsumoto (Mitsubishi Research Institute)

\section{References}

1) Reports [in Japanese] by the National Diet of Japan Fukushima Nuclear Accident Independent Investigation Commission, the Investigation Committee on the Accident at the Fukushima Nuclear Power Stations of Tokyo Electric Power Company, the Independent Investigation Commission on the Fukushima Daiichi Nuclear Accident, and the Tokyo Electric Power Company.

2) Special Advisory Committee on Nuclear Power Plant Earthquake Safety, Atomic Energy Society of Japan: Logic of Seismic Safety in the Design and Assessment of Nuclear Power Plants [in Japanese], July 2010.

3) Preventing the Recurrence of a Nuclear Emergency (Part 1) [in Japanese], Journal of the Atomic Energy Society of Japan, 54 (7), 447-451 (2012).

4) Accidents and Disasters at Nuclear Power Plants in the Aftermath of the Great East Japan Earthquake [in Japanese], Journal of the Atomic Energy Society of Japan, 53 (6), 387-400 (2011).

5) Earthquake Damage Sustained by Nuclear Power Plants [in Japanese], Journal of the Atomic Energy Society of Japan, 54 (3), 171-175 (2012).

6) Trends in Probabilistic Risk Assessments of Nuclear Reactor Facilities and Future Prospects [in Japanese], Journal of the Atomic Energy Society of Japan, 54 (1), 45-50; 54 (2), 128-132; 54 (3), 184 190 (2012). 